\title{
Wagner y Nietzsche. El problema de sus relaciones
}

\author{
David Sobrevilla \\ Departamento Académico de Filosofía
}

A Edgardo Albizu con el grato recuerdo de las conversaciones sobre Wagner y Nietzsche que sostuvimos en el Perú.

\section{LA RELACIÓN EXTERNA ENTRE WAGNER Y NIETZSCHE}

La historia de la relación externa entre Wagner y Nietzsche puede ser contada en pocas palabras: Nięzsche conoció a Wagner en Leipzig a principios del mes de noviembre de 1868 en casa del cuñado del compositor, Hermann Brockhaus. Ambos quedaron muy impresionados, y al despedirse de Nietzsche Wagner lo invitóa yisitarlo en Suiza, donde por entonces residía con su compañera Cósima Liszt, quien aún no se había divorciado de su esposo, el dirigente de orquesta Hans von Bülow. En febrero de 1869 Nietzsche recibió la propuesta de la Unjversidad de Basilea para ocupar una cátedra de * filología clásica, pese-alquelaúnenodse habialdoctofado. Poco después de aceptarla y de trasladarse lagSửzaccisitróla đagnecpor primera vez el 28 de mayo en su casa de Tribschen en Lucerna. En los tres años siguientes Nietzsche siguió frecuentando la casa de la pareja, lo hizo hasta 23 veces, hasta que los Wagner -que en 1867 se habían casado- se trasladaron a Bayreuth en abril de 1872. El 22 de mayo de este año, fecha en que se celebraba el 59 cumpleaños del compositor, se colocó la primera piedra del Teatro de Bayreuth, ceremonia para la que viajó especialmente Nietzsche. Dos años después escribió su Cuarta consideración intempestiva Richard Wagner en Bayreuth, en que celebraba al maestro. Posteriormente, del 12 al 30 de agosto de 1876 se realizaron los primeros festivales bayreuthianos y a ellos asistió Nietzsche, retirándose hacia la mitad de los mismos. Hacia fines de octubre del mismo año se volvió a encontrar con Wagner por última vez en Sorrento. Finalmente, 
el 3 de enero de 1878 recibió Nietzsche el último envío del compositor: se trataba de la partitura del Parsifal. A su vez, en mayo del mismo año él escribió su última carta a Wagner, remitiéndole el primer tomo de su obra Humano, demasiado humano. Luego se produjo el alejamiento definitivo entre el compositor y el filósofo. El 13 de febrero de 1883 muere Wagner. Cinco años después, entre mayo y agosto de 1888 Nietzsche critica su obra agresivamente en El caso Wagner y en diciembre del mismo año en Nietzsche contra Wagner. Actas de un psicólogo, que sólo se publicaría póstumamente. El año siguiente sufre Nietzsche un ataque de locura en Turín.

¿Qué fue lo que produjo el acercamiento primero y el alejamiento después entre Nietzsche y Wagner? Porque es extraño: entre ambos no se dio nunca una discusión. Nietzsche ha reconocido que mantuvo siempre la amistad hacia Wagner y que si criticó su obra fue por razones únicamente objetivas y no personales; y por su parte el compositor nunca dio mucha importancia al distanciamiento del filósofo. ¿Qué fue entonces lo que produjo el rompimiento y qué significado tiene?

\section{LA RELACIÓN INTERNA ENTRE WAGNER Y NIETZSCHE}

1. La primera fase de la relación entre Wagner y Nietzsche

A. El acercamiento "Jorge Puccinelli Converso"
1. Wagner

Cuando Nietzsche conoce a Wagner en 1868 y luego lo visita en Tribschen en 1869 el compositor ya era un hombre célebre. Por entonces Wagner había acabado y estrenado El holandés volante (1841, estreno en 1843). Tannhäuser (1842-1845, estreno en 1845). Lohenqrin (1845-1848, estreno en 1850), Los Maestros Cantores (1862-1867, primera presentación en Munich en 1868), además también había concluido El Oro del Rhin (1852-1854) y La Valquiria (1852-1856) y se encontraba trabajando en la terminación del Ocaso (iniciada en 1848), del Sigfrido (comenzada en 1851). Además, ya hacía un buen tiempo que había publicado sus principales escritos teóricos: El arte y la revolución (1849), La obra de arte del futuro, (1849) y los dos tomos de Opera y drama (1851). Todos estos textos pertenecen a la época de Zurich (1849-1858), luego del período de Wagner como Maestro de Capilla que 
había terminado debido a la participación del compositor en la revolución de Dresde en mayo de 1849. Finalmente, en 1865 ya hacía un año que Wagner se encontraba bajo la protección del Rey Luis II de Baviera. En 1866 debió sin embargo alejarse de la capital muniquesa a Tribschen en Suiza por diversas razones, entre ellas por las intrigas que ocasionó su relación con Cósima Liszt, aún ligada al director de orquesta Hans von Bülow.

Wagner había expuesto su planteamiento sobre la obra de arte fundamentalmente en sus escritos de la época de Zurich, en los que se había ocupado profundamente con la tragedia esquiliana. En El arte y la revolución (1847) contraponía el compositor la situación del arte en la epoca griega con la que tenía en su propia época. Mientras la tragedia griega era el arte máximo que reunía en sí poesía, música, representación, danza y pintura, en tanto que ella significaba la expresión de lo más profundo y noble de la conciencia del pueblo, mientras ella consistía en una fiesta religiosa, es nuestro teatro sostenía Wagner- lo opuesto, su negación: un espectáculo ominoso, surgido del bajo interés de la sociedad industrial por ganar dinero y que sólo aspira a proporcionar entretenimiento. La tragedia griega era pues arte, la nuestra sólo es artesanado. Unicamente la revolución puede provocar el renacimiento del arte. Este arte, el arte del futuro, debía comprender en sí el espíritu de la humanidad libre sobre todas las barreras de las nacionalidades. No se trata por cierto -afirmaba Wagner- de que volvamos a ser griegos, pues nosotros conocemos lo que ellos ignoraban: que hay que amar a todos los hombres para acercarnos a nosotros mismos ý poder-encontrat un goce en nosotros mismos. De esta maneräasegreconcilianeApolonyjestis; cuyo mensaje no hay que confundir con el del Cristianismo según el compositor.

En La obra de arte del futuro (1849) sostenía Wagner que hay dos momentos claves en la evolución de la humanidad: el nacional-genérico y el universal-anacional en que nos encontramos. La tarea del presente es por ello según el músico la de hacer del arte helénico un arte humano, que sirva como religión universal. Esta tarea no está librada a un individuo particular sino al pueblo. El arte del futuro deberá además congregar en sí las principales artes que ahora se dan aisladas: la poesía, la música y la danza. El oratorio y la Opera han sido incapaces de lograr realizar esta unión. Conseguirla es la meta del arte musical que Wagner propone. Su objetivo principal debe ser la acción dramática, a cuyo servicio deben estar tanto la música como la danza. 
Opera y drama (1851) se divide en tres partes: 1 . La ópera y la esencia de la música. 2. La actuación y la esencia de la poesía dramática. 3. El arte poético y el musical en el drama del futuro. En opinión de Wagner el error capital de la ópera ha sido hacer de la música, que es un medio expresivo, la finalidad de la obra de arte; y hacer del drama, que es su finalidad genuina, un puro medio. Lo que en verdad hay que conseguir es una síntesis del verso y de la melodía.

El verso, el aporte del poeta, representa el elemento conceptual y produce la melodía del músico. El músico debe interpretar con sentimiento el texto mediante configuraciones inteligentemente calculadas de ritmos, tonalidades, alturas y relaciones tonales. $\mathrm{La}$ concordancia así lograda debe ser reforzada mediante una orquesta que procura modulaciones armónicas y el colorido sonoro instrumental, que se adecúan al acontecer teatral; y gracias a la contribución dramática de los actores cantantes. La orquesta asume con sus muchas voces la tarea que anteriormente le había correspondido al coro operático. La obra de arte debe ser unificada y mantenida en todo su extensión mediante un sistema de motivos que repiten y acentúan las razones del movimiento dramático. Con esta finalidad se debe desconectar frases musicales determinadas de su unión con el verso correspondiente y deben ser repetidas por la orquesta o los cantantes en situaciones dramáticas posteriores, siempre que las representaciones asociadas con fas primeras uniones verbales recuperen un significado especiale(el fortivo nọsólo debe poder recoger en el presente los movimientos pasados del sentimiento, sino que puede mirar también premonitoriamente hacia el futuro). Es de esta manera cómo, mediante una fusión íntima entre palabra y tono, hay que traducir la conceptual en lo musical. (Robert Gutman, Richard Wagner, Der Mensch, sein Werk, seine Zeit. Munich: Heine, 1970: 168-169).

El material apropiado para el drama musical sólo puede ser el mito por ser la única creación procedente del pueblo.

En 1854 Georg Herweg llamó la atención de Wagner sobre el libro El mundo como voluntad y representación del filósofo Arthur Schopenhauer, que el compositor leyó de inmediato. En su biografía Mi vida, señala que el contenido de esta obra de Schopenhauer le era familiar por el libreto del 
Anillo del Nibelungo, que ya había escrito, pero que El mundo como voluntad y representación le permitió comprender muchas cosas que en su propia obra le resultaban enigmáticas, como por ej. la figura de Wotan. Además la lectura del filósofo llevó a Wagner a una praxis musical diferente a la implícita en sus escritos de la época de Zurich y a una concepción teórica también distinta.

Para Schopenhauer el arte tiene como cometido conocer la idea, es decir, la objetivación más directa de la voluntad, el principio nouménico que está a la base del mundo. Todas las artes son en sí mismas objetivaciones de la voluntad, según una jerarquía que va de las más bajas a las más altas. Tan sólo está excluida de esta jerarquía la música, que no se limita a representar las ideas o grados de objetivación de la voluntad, sino que representa inmediatamente la voluntad misma. La música no es pues una imagen de las ideas como las otras artes, sino de la propia voluntad. Por ello mismo, al considerar la relación que debe existir entre música y palabra, manifiesta Schopenhauer que no cabe que la primera esté al servicio de la segunda, sino a la inversa: la palabra se debe plegar al valor universal de la música.

La concepción schopenhaueriana del arte hizo cambiar a Wagner, en especial porque modificó sus ideas sobre la relación entre la música y la palabra. Si en los escritos de la epoca de Zurich había dado una preeminencia a la palabra, la lectura de El mundo como voluntad y representación debía conducirlo a privilegiar la música. Esto sucedió inicialmente en su praxis musical: en el Tristán (1857-1859) y en fos maestros cantores (1862-1867). En ambos casos es claro que el fexto es desbordado ampliamente por la música, con el agravante de que Wagner hacía caso omiso de la aversión mostrada en Opera y drama hacia la ópera italiana, al introducir en Los maestros cantores muchas de sus formas: arias, marchas, coros, un quinteto $\mathrm{y}$ un ballet.

El evidente cambio en el Tristán procuró justificarlo en su escrito de 1840 Música del futuro. Allí sostenía que la música era el elemento más poderoso en la unión con el drama poetizado.

El drama cumplía ahora sólo un papel unitivo entre el mundo metafísico e ideal de la música y el mundo material y conceptual de los oyentes; el drama era la "expresión plástica", que servía para interpretar el idioma abstracto de los sentimientos de la música. Esta no era más, como en Opera y drama, la expresión más intensa 
pero paralela del texto. La poesía debía apuntar a que su exigencia más íntima y su finalidad última, fuera unirse con la música, "desaparecer" en ella, aunque a la música le falta cuando llega al público un factor esencial, que sólo puede llenar la poesía; la capacidad de dar una respuesta a la pregunta “¿por qué?”. "Esta pregunta incómoda y, sin embargo, ineludible", puede ser respondida, si la poesía se une a la música y se vincula al mundo de las apariencias. Unidas poseen estas artes el poder de sumir a las gentes en un estado de éxtasis, en que no se formulan más preguntas y se da todas las respuestas. (Gutman, Op. cit. 330).

Por lo demás, la influencia de Schopenhauer se hace sentir también a otro respecto: en lo concerniente a las consideraciones del filósofo y de Wagner sobre la relación entre el mundo onírico y el de la vigilia. Schopenhauer había sostenido en Parerga y Paralipomena que cuando el "órgano del sueño" es sobreexcitado en el estado intermedio entre el sueño y la vigilia, el hombre entra en contacto con la voluntad metafísica que no es aprehensible en conceptos pertenecientes al mundo de las apariencias, sino sólo por medio de alegorías. Estas manifestaciones metafísicas que se confunden con las fenomenales son, según Schopenhauer, los sueños proféticos. Pues bien, en Meistersinger Wagner beneficia esta idea presentándola de la siguiente manera: Walter sueña en la canción ganadora y Hans Sachs lo ayuda a descifrarla. Sachs le asegura que el arte y el sueño son lo mismo, ya que la poesía no es otra cosa que la interpretacion de los sueños. Ambos se encuentran en una relación amigable " $y$ sesayudaffel uno ap otror. Peło si a alguien le falta el arte de descifrar el sueño, el tratar de hacerlo se le convierte en una pesadilla, como a Sixtus Beckmesser.

Wagner también aplicó las ideas de Parerga y Paralipomena en su gran artículo Beethoven de 1870. Allí sostiene que al lado del mundo onírico de la imagen hay un mundo auditivo místico, que comunica a los oyentes experiencias auditivas telepáticas, que corresponden a los fenómenos de la clarividencia y de la visión profética y que posibilitan que la música alcance la conciencia. En su discurso con motivo de la colocación de la primera piedra del Teatro de Bayreuth en 1872, Wagner hablaba de "imágenes escénicas, que parecen representarse... a partir de un mundo onírico ideal”. Estos esquemas de la voluntad del mundo que surgen del sueño del artista, debían proporcionar al espectador noticia de la realidad íntegra de la ilusión plena de sentido de un arte noble. El afán de crear un mundo de ensueño en la escena explica 
muchas de las indicaciones que dio Wagner al arquitecto Semper para la construcción del Teatro de Bayreuth.

En realidad no sería justo presentar la evolución de Wagner en cuanto a su concepto de las relaciones entre música y palabra como lineal e irrevocable. Si en Beethoven y en Sobre el destino de la ópera de 1871 sostenía el compositor la preeminencia de la palabra, en el escrito Una mirada sobre la ópera alemana actual de 1872 afirmaba que el texto del drama musical constituía el "verdadero contenido de la obra". En el artículo Sobre la denominación "Drama musical", también de 1872, manifestaba que la música se preparaba para "retomar su vieja dignidad como seno materno del drama", y no como su rival sino como su madre. No obstante, en el artículo "Sobre el poetizar y el componer operático" de 1879, sostenía que la poesía era el principio varonil conformador del drama musical. Un año más tarde revisaba su opinión en Religión y Arte expresando que la música "disuelve" la perceptibilidad de las palabras hasta hacerla desaparecer y comunica entonces su puro contenido emotivo tan sólo a lansensación arrobada, y pone de manifiesto "la esencia más íntima de la teligión cristiana", por lo que puede pasar como "el movimiento del dogma divino-liberador de la variedad del mundo de las apariencias" (puede verse sobre las oscilaciones wagnerianas el libro mencionado de Gutman).

Estos son algunos de los planteamientos de Wagner por la época en que se encuentra con Nietzsche. Consideramos ahora la evolución de este último. "Jorge Puccinelli Converso»

\section{Nietzsche}

En 1868 Nietzsche era un distinguido alumno de filología. Estudiaba bajo la dirección del Profesor Friedrich Wilhelm Ritschl: en 1865 había descubierto a Schopenhauer -que por entonces ya había fallecido, comenzaba a ser más conocido, pero aún no disfrutaba de una gran popularidad-, y en 1866 había iniciado su amistad con el también estudiante de filología Erwin Rohde. En aquella época, Nietzsche ya empezaba a sentirse desengañado del poco influjo que ejercía la filología sobre su ambiente, de su esterilidad; y se puede encontrar anotaciones en las que confesaba que deseaba abandonar estos estudios para dedicarse ya sea a la ciencia natural o a la filosofía. Estos propósitos le fueron sugeridos por la lectura de Schopenhauer y de F. A. Lange. 
No obstante, no llegó a abandonar tan pronto la filología clásica, porque en febrero de 1869 Ritschl recibió la solicitud de la Universidad de Basilea de ocupar una cátedra en ella. Al no aceptarla, trasmitió el pedido a Nietzsche, y la Universidad estuvo de acuerdo con su nombramiento. El hecho es significativo no sólo porque entonces Nietzsche únicamente tenía 25 años, sino además debido a que, como manifestábamos, por entonces él no había obtenido un doctorado. Este es uno de los pocos casos en la vida académica de lengua alemana, en que se pasó por encima del requisito de poseer un grado para otorgar una cátedra.

Antes de conocer a Wagner, Nietzsche ya tenía una visión filosófica propia que se había formado a la luz de las lecturas de Schopenhauer y de F. A. Lange. De Schopenhauer había tomado Nietzsche algunas ideas esenciales -como la de la voluntad como realidad fundamental más allá de las apariencias, que no tiene ningún telos final y que es indestructible, su idea del genio, su repulsa de la vida contemporánea. De Lange había asumido que el conocimiento de lo metafísico y de lo suprasensible es inviable y que el conocimiento religioso es imposible. Én estas condiciones, la especulación, la religión y la poesía quedan niveladas como fenómenos estéticos. Sobre la base de esta conclusión, el joven Nietzsche criticaba a Schopenhauer haber hecho del concepto de la cosa-en-sí una categoría escondida, cuando en verdad sólo podría ser aprehendida con una intuición poética; el haber atribuido determinados predicados a- la cosa-en-sí-unidad, eternidad, libertad-, atributos que sólo tienen sentido en relación a la esfera del conocimiento humano; y el no haber comprendido que su sístema involucra diversos problemas como el de la individuación.

Por la época en que Nietzsche conoce a Wagner comienza a edificar su planteo propio. En su opinión la realidad es lo proto-uno que en sí mismo es reposo eterno y puro ser. En tanto realidad última es algo incognoscible e indescifrable. Esta realidad es proto-dolor y proto-contradicción. Al salir fuera de sí se manifiesta como algo múltiple, como un ser empírico: el devenir o la apariencia. En tanto lo otro, es apariencia, protoplacer y armonía. El juego del dolor y el placer constituye consonancias y disonancias. La música da origen a la voluntad y es de otro lado su objeto. Pero con lo dionisíaco no se logra solucionar la contradicción de lo proto-uno, sino que se necesita una nueva apariencia: lo apolíneo de la ilusión. Esta tiene como medio la representación: una imagen, una ilusión sin realidad. El mundo consta de ambas instancias: de la voluntad y la apariencia. Al contemplarse la voluntad en las 
imágenes siente un placer máximo, porque se origina un exceso (de placer) que supera al dolor. De aquí surge lo bello. En este momento se encuentran el proto-ser y el devenir, el protodolor y el protoplacer, la realidad y la apariencia y se disuelve la contradicción de lo Uno. Lo que no significa que termine el dolor, porque entonces también concluiría el placer, sino sólo que se ha cerrado una onda.

Este proceso pensaba Nietzsche que se repite en el hombre. Está en la naturaleza de cada ser humano ascender hasta donde pueda; hay que establecer una diferencia entre el hombre corriente y el genio. El hombre corriente no tiene conciencia del proceso artístico en que se encuentra; el genio, que posee una naturaleza apolínea, sí. El genio es nutrido por el pueblo y el destino de éste depende a su vez del desarrollo de aquél. Hay dos clases de genios: el teórico y el artístico. El primero da respuesta a la pregunta por el origen de las cosas, el segundo repite en sí el proceso primordial. El arte no es otra cosa que la capacidad de producir el mundo de la voluntad sin que el producto quiera a su vez.

Nietzsche ha desarrollado en su época de Leipzig y de Basilea además una crítica y una filosofía de Ta cultura. En su opinión la cultura es la unidad del estilo artístico en todas las manifestaciones vitales de un pueblo. Esta unidad es mediada por un mito; así en la cultura semita por el mito del pecado original y en la aria porel de Prometeo Una cultura supone una pluralidad de impulsos -el cognoscitivo, el artistico, el metafísico- y el predominio y control por parte de uno de ellos. Es asi como ser originan distintos tipos de culturas. La cultura budista acentúa el impulso metafísico, la socrática el del conocimiento y la trágica el artístico.

La cultura moderna, alejandrina o de la ópera no representa otra cosa que la exacerbación de la cultura socrática. El historismo ha ingresado en lugar del mito y propende a la nivelación de la diferencia entre el hombre medio y el genio. Otros rasgos de esta cultura son la formación superficial, el afán del Estado de ser un fin en sí mismo, el eruditismo y el periodismo.

El ideal de la cultura de Nietzsche no implica tan sólo la vuelta hacia la cultura griega sino la creación de un nuevo tipo de cultura, que reúna en sí los rasgos de la filosofía y del arte. No obstante el indudable carácter negativo de la cultura de su tiempo, Nietzsche creía encontrar signos alentadores que indicaban el surgimiento de este nuevo tipo de cultura. El veía estos 
signos en el renacimiento de la filosofía alemana con Kant y Schopenhauer, y en el renacimiento de la música alemana con Wagner.

\section{El acercamiento}

\section{a) Wagner}

Las razones para la acogida que Wagner dispensó a Nietzsche, pensamos que son fundamentalmente tres.

En primer lugar es bastante conocido y ha sido estudiado muchas veces que el mundo académico alemán era hostil hacia el compositor, de modo que Wagner sólo puede haberse alegrado cuando se acercó a él el joven y brillante catedrático de la Universidad de Basilea, que además era afecto al arte y versado in musicis y que atrajo al círculo wagneriano a otros académicos jóvenes como a Erwin Rohde.

Segundo, Wagner vio en Nietzsche a un excelente colaborador, que podía prestarle grandes servicios: ser un propagandista de la causa de la obra de arte del futuro y cooperar con él en asuntos mayores y menores, como escribir un manifiesto en favor de Bayreuth, velar por la educación de sus hijos, corregirle sus manuscritos, realizar compras y atender distintos asuntos.

Tercero, y esto es probablemente, lo mas importante, Nietzsche era el interlocutor ideal para Wagner tanto en lo relativo a los temas griegos, que habían preocupado intensamente al compositor en Zurich, como en lo concerniente a la filosofía de Schopenhauer y sus consecuencias para la música y el drama musical. A este respecto son reveladoras las analogías entre las ideas de Wagner sobre el mundo auditivo de la música y el visual y onírico de la escena, con el planteamiento de Nietzsche sobre el nacimiento de la música provocado por el dolor de la voluntad y el placer de la apariencia, y sobre la génesis de la ilusión a partir de la música. Por lo demás, en ambos casos hay una independencia innegable de los pensamientos expuestos por Schopenhauer, sobre todo en Parerga y Paralipomena.

Todo lo anterior creemos que explica lo suficiente las razones de Wagner para escribir que Nietzsche era, con Cósima, lo único bueno que la vida le había deparado. 


\section{b) Nietzsche}

Por parte de Nietzsche hay sin duda más razones para la aproximación a Wagner. Primero: la comunidad que sentía el Profesor de Basilea con el compositor debido a su admiración por los griegos, por Schopenhauer y por la música.

Segundo, Nietzsche veía a Wagner como a un genio en contradicción con la cultura de la ópera imperante, y como a un renovador de la música alemana y, por lo tanto, de la cultura de su tiempo.

Tercero, Nietzsche encontró muchas sugerencias y anticipaciones para sus propios pensamientos en El nacimiento de la tragedia a partir del espíritu de la música (1872) en Wagner. Así el compositor le llamó la atención sobre el libro El Apolo Vaticano en que Amselm von Feuerbach ya había prefigurado la oposición nietzscheana entre lo apolíneo y lo dionisiaco. Por otra parte, Wagner sostenía que el coro debía ser la realización danzante plástica del elemento musical de la tragedia. Por último, aun la idea nietzscheana del nacimiento de la tragedia del espíritu de la música se halla en los escritos wagnerianos de la época de Zurich.

Todos estos influjos se unieron en la composición de los escritos preparatorios a El nacimiemto dela tragedia y en la redacción final de este libro. No obstante, hay que señalar también las diferencias: mientras a Wagner lo que le interesaba era la superación del ideal clasicista del arte y esto mediante la acentuación ya sea de la superioridad de la poesía o de la imagen sobre la música; o a la inversa: para Nietzsche lo fundamental era la tensión entre lo apolíneo y lo dionisiaco, que constituía para él la esencia del arte trágico. Ahora es bien conocido que cuando el bosquejo del Nacimiento de la tragedia, que llevaba como título El origen del pensamiento trágico, fue leído en abril de 1871 por los Wagner, ambos no pudieron ocultar su decepción, ya que el texto no trataba del compositor, de modo que Nietzsche debió de cambiar el manuscrito original, lo que le acarreó problemas conocidos con su ex compañera de colegio Ulrich von Willamowitz-Möllendorf.

\section{El alejamiento}

Muchas son las razones que se han esgrimido para explicar el proceso de alejamiento y extrañamiento entre Wagner y Nietzsche. Algunos piensan que 
las razones fundamentales son de índole psicológicas: Wagner habría sido una naturaleza extrovertida y habría tenido un gran éxito en la vida, mientras que Nietzsche habría poseído un carácter introvertido que había sido marcado por el fracaso. A esto se habrían añadido por parte de Wagner: su desagrado al observar que no podía servirse dúctilmente del joven filósofo, su decepción al observar que Nietzsche no seguía escribiendo sobre él -es característica al respecto la reacción de Cósima al recibir a comienzos de 1874 la segunda de las Consideraciones intempestivas: se puso a corregir ella, que procedía de una familia austro-húngara, que había nacido en Italia y se había educado en Francia, a uno de los estilistas más consumados del idioma alemán como es Nietzsche; o su ira al visitar un día el filósofo a Wagner en Bayreuth con el Canto Triunfal de Brahms bajo el brazo- en 1874 también. Por parte de Nietzsche se agregan a lo anterior sus celos por la relación entre Wagner y Cósima, de la que él estaba enamorado, el desagrado que le causaban las actitudes tiránicas de Wagner, la carta que el compositor escribió al médico del filósofo en 1877 indicándole que, en su opinión, los dolores que ya por entonces sufría Nietzsche se debían a excesos masturbatorios y recomendando una cura de agua.

Otros opinan que lo determinante en el alejamiento entre Wagner y Nietzsche fueron razones políticas: el filósofo no podía sufrir el antisemitismo del compositor, su desdén por Francia, su actitud obsecuente ante los príncipes y sobre todo que para poder mantener los festivales de Bayreuth se inclinara frente a la mismai eligarguía inculta a la gue antes había atacado.

Finalmente hay quienes succinelli Conyerso" actitud divergente en relación a la religión y el cristianismo: mientras Nietzsche había rechazado la solución religiosa al problema de la vida, y pensaba que el cristianismo era "platonismo para el pueblo", Wagner se había vuelto hacia la religión y el cristianismo en el Parsifal, abjurando tácitamente de su confesado ateísmo anterior. Por lo tanto, el rompimiento habría sido inevitable cuando en 1878 el compositor envió al filósofo la partitura del Parsifal. En contra de esta posición señala con acierto Dietrich Fischer-Diskau (Wagner und Nietzsche. Stuttgart: Deutsche Verlag-Anstalt, 1974: 56) que Nietzsche conocía el libreto de este drama musical desde la Navidad de 1869, en que el propio Wagner se lo leyó: por lo que de ser cierto este punto de vista, el rompimiento debería haberse producido mucho antes.

Nosotros pensamos que en todas estas opiniones hay algo de verdad, pero que no llegan a tocar las razones fundamentales para el alejamiento entre 
Wagner y Nietzsche. Antes de ocuparnos de ellas, quisiéramos referirnos a dos hechos un tanto superficiales y ajenos al rompimiento, pero que creemos que sin embargo tuvieron una inocultable repercusión en relación al mismo. Todos los investigadores que se han ocupado del distanciamiento entre Wagner y Nietzsche señalan que es muy difícil fijar cuándo comenzó a tener lugar. Aventuramos que la razón es que en realidad fue paulatino, Wagner se dio cuenta poco a poco de que no podía contar con Nietzsche incondicionalmente para sus propósitos, y el joven profesor de filología que en verdad no existían las coincidencias entre sus opiniones y las del compositor que inicialmente había supuesto. En el caso de Nietzsche, su afecto por Wagner postergó por un largo tiempo la decisión del alejamiento: tan sólo a regañadientes admitió que más pesaban las razones objetivas para la ruptura. Lo segundo es la partida de los Wagner de Tribschen en abril de 1872. La distancia física dio lugar a que los malentendidos no pudieran disiparse en medio de la conversación, y a que Wagner no pudiera hacer uno de su conocida capacidad suasoria. Ahora hay que tener en cuenta que este segundo hecho no fue decisivo: tan sólo aceleró el alejamiento que, aunque los Wagner hubieran seguido en Suiza, se hubiera de todos modos producido, ya que en realidad era inevitable.

Lo determinante para el distanciamiento entre Wagner y Nietzsche pensamos que fue su distinta concepción de la realidad y de la obra de arte. Ambos habían partido de las ideasde Schopenhauer, para quien a la base del mundo se halla la voluntad que esciega, que que provoca el sufrimientorgeas unicasesoluciones posibles eran para el autor de El mundo como voluntad y representación que el hombre llegue a entrever intelectualmente el mecanismo de la voluntad y se retraiga de su engaño gracias al arte o por medios quietivos como las ascesis y la compasión. El arte sólo procura una solución momentánea, ya que en la contemplación artística entramos en comunicación con el ser auténtico del mundo sin las turbiedades procedentes de las ilusiones provocadas por la voluntad. La solución procurada por la ascesis y por la compasión son en cambio definitivas.

Ahora bien, Wagner aceptaba las ideas básicas de Schopenhauer, pero a diferencia de él sostenía que no es conscientemente como el hombre advierte el engaño de la voluntad y se libera sometiendo a ésta al yugo del intelecto, sino que creía que el hombre se "redime" de la voluntad a través del renunciamiento intuitivo. Por ello despreciaba la razón; además sostenía que hay que reconciliar a Apolo con Jesús y en sus últimos años se había aproximado 
otra vez a la Iglesia. La idea fundamental del Anillo del Nibelungo no es en el sentido que se acaba de exponer- otra que la acusación formulada por Wagner contra la voluntad y los males que acarrea, y el Parsifal postula que para "salvarse" de esta voluntad hay que predicar un renunciamiento que posee un carácter religioso y que hay que colocar el sufrimiento a la misma altura que la compasión de Schopenhauer.

En cambio, Nietzsche -que estaba de acuerdo con Wagner contra Schopenhauer, en que el arte procura una solución al problema de la voluntad y de la vida- no creía que fuera ni por un acto de "renunciamiento" ni menos de carácter religioso, que se lo logra. Por el contrario, de lo que se trata es de afirmar la voluntad de poderío y de negar la realidad de la individuación y del dolor; y además de rechazar terminantemente toda vuelta hacia lo religioso y la consecuente postulación de un "trasmundo", esto es de valores trascendentes y eternos. De allí que Nietzsche sostenga que el cristianismo no es otra cosa que "platonismo para el pueblo".

Por otra parte, Wagner y Nietzsehe tenían a la larga que separarse, porque su respectiva concepción de la obra de arte y del drama musical o de la tragedia era muy diferente. Para ambos el arte trae una solución al problema de la voluntad y de la vida, pero en forma muy distinta. En Wagner hay la idea de que el elemento inconsciente del arte debe tener una primacía sobre el conciente y la músicasobre la palabra -aunque como hemos visto a veces sostenía a este último respecto to contrario: que era la palabra la que debía destacar sobre la música. Pof cohfra, la opinion mẩs gẻnuina de Nietzsche era que en la tragedia existía una tensión sobre lo dionisíaco y lo apolíneo, entre la música y la imagen; y que ningún elemento debía preponderar sobre el otro.

Las observaciones críticas de Nietzsche sobre Wagner se fueron acumulando en nuevos fragmentos desde la época de El nacimiento de la tragedia a partir del espíritu de la música. Por último, encontramos una primera expresión equívoca, aunque al final terminante, cuando en la Cuarta consideración intempestiva: Richard Wagner en Bayreuth el compositor es presentado como una naturaleza ambigua: de una parte aparece como teniendo un gran vigor y moviéndose en la esfera de una "voluntad violenta" y destructiva; y de otra como una fuerza de libertad de claridad, de amor, de dulzura. El primer impulso da lugar al arte de Wagner con una tendencia a ensordecer a sus oyentes, a violentarlos, a conmoverlos por la fuerza. La otra esfera origina en cambio un arte que libera de la violencia de la voluntad, que limita el impulso 
del poderío. Ahora bien, Nietzsche pensaba que para poder tener éxito en su época Wagner tenía que acomodarse a sus condiciones, lo que significaba: desarrollar el impulso de la voluntad violenta y destructiva. Y creía además que aún no existe el público para el gran arte de Wagner, que es el de la segunda esfera; y es por eso que la segunda posibilidad de poner este arte en escena en Bayreuth dependía de que se produzca un cambio en el espectador $y$ en el mundo.

\section{La segunda fase de la relación entre Wagner y Nietzsche}

La segunda fase de la relación entre Wagner y Nietzsche luego del alejamiento, no presenta una gran reacción por parte del compositor. Pareciera que éste, convencido de que el filósofo no le era útil, no quiso dar mayor importancia al distanciamiento. Para los trabajos en relación a los cuales había pensado en Nietzsche atrajo hacia sí a otros jóvenes. Así por ejemplo para proveer a la educación de sus hijos tomó elDr. Heinrich von Stein, que habría que visitar posteriormente a Nietzsche (en-1884) y escribir dos años después su excelente estudio El origen de la estética moderna (1886). En cuanto a la crítica que Nietzsche empezaba a exteriorizar en Humano, demasiado humano, la contestó sin nombrar al filósøfo en la tercera entrega del artículo "Público y popularidad" de 1878 , en que manifestaba que un artista no puede tomar en cuenta al públice, que do bueño sóletaparece bajo la figura del término medio, atacando de paso a los "profesores" aunque sin mencionar a Nietzsche. A Overbeck le escribio que conservaba un sentimiento de amistad para con Nietzsche, que no había leído Humano, demasiado humano, y que esperaba que el filósofo supiera apreciar su gesto. En su círculo de admiradores, Wagner quiso atribuir la nueva actitud nietzscheana para con él a la influencia del nuevo amigo de Nietzsche el médico judío Fanl Rée: "Los escritos de Nietzsche son Rée-kleckse" -deposiciones de Rée, decía. Por último, cuando alguien le recordaba que antes lo había elogiado Nietzsche, respondía que no le eran ningún gran honor las alabanzas de ese señor.

Luego de la muerte de Wagner y cuando cada vez más se conocieron los ataques de Nietzsche, Cósima declaró que ellos revelaban sus malas costumbres. No obstante, a la muerte del filósofo y cuando éste ya se había convertido en una personalidad muy famosa, debe haberle propuesto su hermana, Elisabeth Förster-Nietzsche, a Cósima que ambas juntas presidieran los festivales de Bayreuth. 
En cuanto a Nietzsche, sufrió profundamente con la separación. En Ecce Homo escribió sobre la música de Wagner que "el mundo se empobrece para quien no ha estado lo suficientemente enfermo como para gozar de estas delicias del infierno". El veía su relación con Wagner como la de Bruto: la grandeza de la víctima se corresponde con la del victimario. Nietzsche discute cuán grandiosamente representó Wagner la relación entre Wagner y Sigfrido: "El amor y la enemistad obligada", dice, "esto es altamente simbólicos para la esencia de Wagner". En La Gaya Ciencia (1881-2) escribe: "Independencia del alma -esto es lo que vale aquí-. Ninguna ofrenda puede ser a este respecto demasiado grande. Hay que saber victimar aun a su mejor amigo, pese a que sea el hombre más hermoso, un adorno del mundo, un genio sin igual". En el Sanctus Januarius de La Gaya Ciencia manifiesta: "el haber tenido que separarnos fue ley entre nosotros; presiento que a través de este alejamiento nos hemos dignificado más".

Nietzsche sentía por lo tanto que se había visto obligado a romper con Wagner, pero humanamente continuaba vinculado con él. Así hablaba en Ecce Homo de "la hora sagrada en que murí́ Richard Wagner en Venecia": y Lou Andreas Salomé nos ha dado una imagen estremecedora de una visita que realizó a Tribschen con Nietzsche que hablaba con voz trémula de los días dichosos que había pasado allí con los Wagner al tiempo que se le llenaba los ojos de lágrimas.

\section{Biblioteca de Letras}

Aun en los escritos más yitriólicos de Nietzsche contra Wagner se siente que era conciente de su grandeza. Estos escritos son El caso Wagner y Nietzsche contra Wagner, Actas de un psicólogo. En ambos Nietzsche deja el aspecto positivo que en Richard Wagner en Bayreuth había reconocido al arte de Wagner $\mathrm{y}$ ataca inclementemente su lado negativo. En el primero sostiene que la música de Wagner es nórdica y decadente, a diferencia de lo que sucede con la de Bizet. Que el problema principal de Wagner es el de la "redención". Que en El Anillo del Nibelungo Wagner sustituyó su optimismo maternal por el pesimismo que aprendió de Schopenhauer. Que su música es enfermiza. Que la melodía es inmoral sin un equilibrio y el motivo conductor una cuestión culinaria. Que el verdadero arte wagneriano es el de la miniatura. Que es terrible su capacidad hipnótica. Que en Wagner el teatro y, mejor, la comedia, se ha sobrepuesto a las otras artes y la música se ha convertido en el arte de la mentira. Pero todas estas críticas las formula Nietzsche después de aceptar que Wagner resume la modernidad y en su afán de superar a ésta. 
En Nietzsche contra Wagner ha tratado de explicar el filósofo lo que admiraba en Wagner, cuáles son las objeciones que le hacía, por qué consideraba al compositor un peligro y a su música sin porvenir, y por qué se separó de Nietzsche por razones puramente objetivas, porque sobre su amistad nunca se cruzó una nube, escribe.

\section{CONSIDERACIÓN FINAL}

En resumen podemos decir que Wagner y Nietzsche se acercaron por razones diversas, pero en el fondo porque tenían una profunda comunidad en el momento en que se encontraron debido al impacto que en ambos había hecho Schopenhauer: los dos pensaban que la voluntad constituía un problema para el hombre, ya que trae objetivamente dolor.

Pero se separaron al planteaf soluciones diferentes a la dificultad que habían encontrado: mientras Wagner postulaba al final de su carrera que la solución se encuentra en el renunciamiento, Nietzsche sostenía que lo que más bien cabe es potenciar Tá volurtad, yarque lo que en fin de cuentas importa es lo que se crea: la obra de arte que justifica la existencia. Mientras el compositor se volvió al término de sus días al Cristianismo en el Parsifal. Nietzsche se resolvió por una inversión de los valores cristianos.

En fin de cuentas lo cute etefistariciamiento entre Wagner y Nietzsche

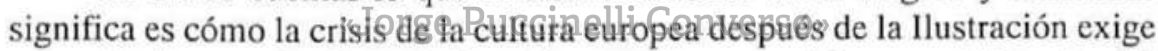
una solución que fue formulada en forma diversa por Wagner y Nietzsche. El primero ensaya diversas propuestas al problema de la voluntad en sus distintas obras, en especial en El Anillo del Nibelungo, para finalmente retornar al Cristianismo en una interpretación muy personal que subraya cómo la "redención" nos libera de la voluntad y del dolor que causa. En cambio, Nietzsche decide potenciar la voluntad a fin de que, logrando una cierta altura consiga crear obras de arte que enriquezcan el mundo y justifiquen estéticamente la existencia, y rechaza los valores cristianos por esclavizar al hombre e impedir el tránsito a una nueva cultura y a una nueva humanidad. En tanto estas dos soluciones eran incompatibles, el distanciamiento entre Nietzsche y Wagner fue, como dijimos inevitable. 